\title{
5 Six Arguments for Wh-Movement in Chamorro
}

Sandra Chung

\subsection{Introduction}

Since Seiter 1975, it has been known that constituent questions in many of the verb-initial Austronesian languages are headless-relative clefts (henceforth, HRCs) complex sentences in which the interrogative phrase serves as a nonverbal predicate and the rest of the sentence serves as its subject, a headless relative clause. (See, e.g., Potsdam 2004 and Paul and Potsdam 2004 on Malagasy; Bauer 1991 on Maori; Georgopoulos 1991 on Palauan; Seiter 1975 on Tagalog and six other Philippine languages; and Aldridge 2004 on Tagalog and Seediq.) In these languages, Greenberg's (1963) claim that VSO languages always place their interrogative phrases at the left (the first half of his Universal 12) is satisfied not by wh-movement of these constituents, but by virtue of the fact that interrogative phrases can be predicates, and predicates are clause-initial. The observation leads to a speculation, one explored in different ways by, for example, Adger and Ramchand 2005 and Oda 2005. Could it be that $w h$-movement of interrogative phrases is systematically lacking in verb-initial languages, just as it has been claimed to be systematically lacking in SOV languages (the second half of Universal 12)? If so, the typological distribution of wh-movement would be narrower than is often supposed, and a host of other issues would immediately arise. ${ }^{1}$

This chapter brings evidence to bear on this speculation from Chamorro, a verbinitial Austronesian language spoken in the Mariana Islands. Some constituent questions in Chamorro can be analyzed either as HRCs or as derived directly by wh-movement of the interrogative phrase. I show that other types of Chamorro questions are not structurally ambiguous in this way: these other questions cannot be analyzed as HRCs, but must instead be derived by $w h$-movement of the interrogative phrase. More generally, there are types of focus constructions in Chamorro that cannot be analyzed as HRCs, but must instead be derived by wh-movement of the focus. The demonstration reveals that there are verb-initial languages-and, for 
that matter, Austronesian languages - that can satisfy Greenberg's Universal 12 via straightforward wh-movement.

\subsection{Preliminaries}

Chamorro is a null-argument language in which the predicate can be of any category type. When the predicate is a verb or an adjective, it can be followed by its arguments in any order, but the unmarked word order is Predicate Subject Complements- that is, VSO, as in (1a).

(1) a. Ha-konfitma i kotte i intensión i Covenant Agreement. AGR-confirm the court the intension the Covenant Agreement 'The court confirmed the intention of the Covenant Agreement.' (Saipan Tribune, September 1, 2000)

b. Hägas ha-läknus ennao siha na planu si Speaker Benigno R. Fitial. long.ago AGR-present that PL L plan UNM Speaker Benigno R. Fitial 'Speaker Benigno R. Fitial presented those plans long ago.' (Saipan Tribune, September 14, 2000)

When the predicate is a noun or preposition, the entire predicate phrase (DP or PP) precedes the subject, as in (2).

(2) a. Ti médiku esti siha na siñores.

not doctor this PL L gentlemen

'[The public is fortunate that] these gentlemen are not doctors.' (Saipan

Tribune, June 8, 2000)

b. Ginin i asagua-ña gi fine'nena dos haga-ña.

from the spouse-AGR LOC first two daughter-AGR

'Two of his daughters were from his first wife.' (Cooreman 1982, 8)

DPs are inflected for case via a proclitic at their left edge. There are three morphological cases-unmarked, oblique, and local-whose realizations are different for pronouns, proper names, and common nouns.

(3) Duranti-n ädyu na tiempu [änai sigi i dos di um-äpatti ni pigua' _ ], during-L that $\mathrm{L}$ time COMP keep.on the two AGR-divide OBL betelnut guäha un patgun [mamómokkat__ gi chälan].

AGR.exist a child WH[nom].AGR.walk.PROG LOC road

'During that time when they were dividing the betelnuts, there was a child who was walking on the road.'

Of special interest here is the internal structure of DP. DPs consist of a determiner, followed by an NP and then by a possessor. Relative clauses and other modifiers can occur adjoined to the left or to the right of an NP. 
(4) a. i hägas songsung [nai dumángkulu gui' yan mañe'lu-ña _ ] the long.ago village COMP AGR.big he with siblings-AGR 'the long-ago village in which he grew up with his brothers and sisters' (Saipan Tribune, June 15, 2000)

b. gi todu [nai sumaonao__ ] na programa-n radio LOC all COMP AGR.participate $\mathrm{L}$ program-L radio 'in all radio programs in which he has participated' (Saipan Tribune, June 25, 2000)

As (3) and (4) show, relative clauses contain a DP gap (represented by an underline) but no overt relative pronoun. Nonetheless, the dependency between the gap and the head NP meets the standard criteria for wh-movement: it holds across an apparently unbounded distance, observes islands, and exhibits strong crossover effects (see Chung 1998, 214-221). The only open question is what element it is, exactly, that has been moved. I will arbitrarily assume that the answer is not the head NP, but rather a null DP operator, $O$, which can serve various grammatical functions but must undergo $w h$-movement to the specifier of the highest $\mathrm{C}$ in the relative clause. This null operator can serve as a DP argument, or as any of the adjuncts realized as DPs in the oblique or local case-specifically, instruments, manner phrases, or locations in time or space. $^{2}$

Finally, the head NP of a relative clause can itself be null, in which case it contributes no descriptive content. In such cases, certain complementizers that realize the highest $\mathrm{C}$ of the relative clause are also unpronounced (see Chung 1998, 231234, for the details). Compare

(5) a. Um-äsudda' häm yan i palao'an [ $O$ ni kinenne'-ña si AGR-meet we with the woman COMP WH[obj].take-AGR UNM Manuel_pära i giput].

Manuel to the party

'I met the woman who Manuel took to the party.'

b. Esta ti máfattu gi banda-n [ $O$ änai man-gaigi todu i already not AGR.arrive.PROG LOC side-L COMP AGR-be.at all the manbihu _ ].

old.ones

'He hadn't yet gotten to the place where all the old men were.' (Cooreman 1983, 65)

(6) a. Um-äsudda' häm yan i [ $O$ kinenne'-ña si Manuel_pära i AGR-meet we with the WH[obj].take-AGR UNM Manuel to the giput].

party

'I met the one who Manuel took to the party.' 
b. Dumimu guihi [O änai gaigi si tata-ña yan si AGR.kneel LOC.that COMP AGR.be.at UNM father-AGR and UNM nana-ña $\quad$ ]. mother-AGR

'They knelt where his father and his mother were.' (Cooreman 1983, 71)

I will refer to a relative clause whose head NP is null as a headless relative (HR).

\subsection{The Issue}

Greenberg's $(1963,111)$ Universal 12 states:

If a language has dominant order VSO in declarative sentences, it always puts interrogative words or phrases first in interrogative word questions; if it has dominant order SOV in declarative sentences, there is never such an invariant rule.

Consistent with Universal 12, Chamorro always places its interrogative phrases at the left. These interrogative phrases are typically DPs or PPs; if they serve as adjuncts or arguments, they cannot occur in situ. ${ }^{3}$ Consider the constituent questions below.

(7) a. Hayi siña luma'la’__ gi $\$ 3.05$ gi ora na suetdu? who? can wH[nom].AGR.live LOC $\$ 3.05$ LOC hour L salary

'Who can live on an hourly wage of \$3.05?' (Saipan Tribune, November 28, 2000)

b. Pära manu guätu na un-konni' si Rita _ ?

to where? over.there COMP AGR-take UNM Rita

'To where did you take Rita?'

c. Hafa malago'-mu? _ ?

what? wH[obl].want-AGR

'What do you want?'

d. Hafa na guäha giya Obyan ädyu i latte stone _?

what? COMP AGR.exist LOC Obyan that the latte stone

'Why would there be those latte stones at Obyan?' (Cooreman 1983, 8)

As expected, the dependency between the interrogative phrase and the gap in constituent questions exhibits the familiar properties of wh-movement (see Chung 1998, 208-214).

It is immediately apparent that questions of type (7) could, in principle, be analyzed in two ways: as constructions in which the interrogative phrase has undergone wh-movement, as shown schematically in (8), or as HRCs (headless-relative clefts) complex sentence types in which the interrogative phrase is a higher nonverbal predicate and the remainder, its subject, is an HR, as sketched in (9). 
(8)

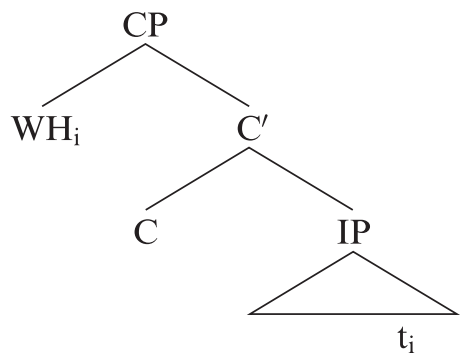

(9)

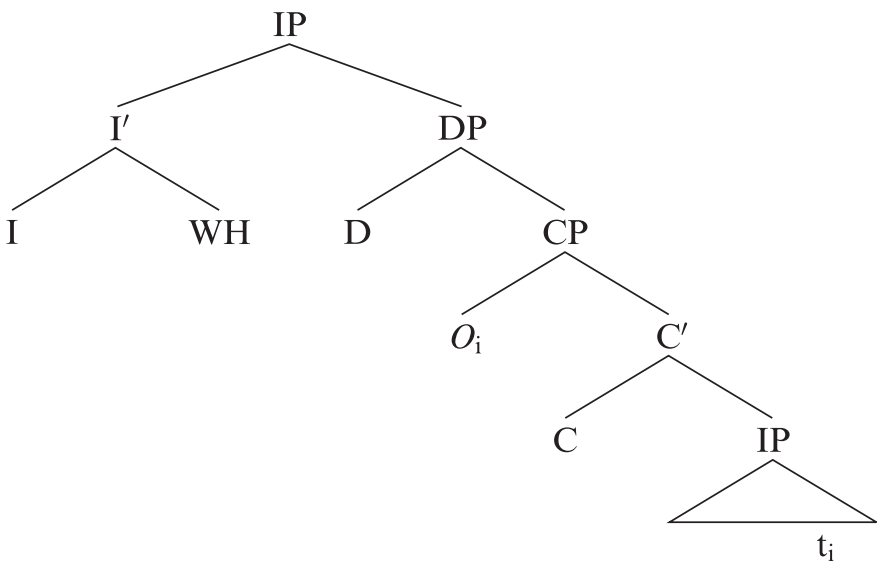

The availability of the HRC analysis follows from the fact that each of its parts is known independently to be available. As shown in section 5.2, Chamorro has HRs. The language also permits interrogative phrases to serve as predicates of clauses, as can be seen from (10).

(10) a. Hayi hao?

who? you

'Who are you?'

b. Hafa i óttimu na che'chu'-ñiha?

what? the last $\quad$ L job-AGR

'What was their last job?'

c. Pära hayi i [O fina'tinas-mu_ _ ] titiyas?

for who? the wH[obj].make-AGR tortillas

'For whom were the tortillas that you made?'

Further, because constituent questions in Chamorro can be viewed as a subtype of focus (or cleft) construction, the choice between a simple $w h$-movement analysis and an HRC analysis arises for the focus construction as well. In the focus construction, the focus - typically a contrastive DP or PP_occurs at the left and is resumed by a gap. Consider 
(11) a. Todu i dos um-aluk na bunitu esti na na'an. all the two WH[nom]-say COMP AGR.pretty this L name 'Both of them said that this name was beautiful.' (Cooreman 1983, 78)

b. I botu-mu míbali the vote-AGR WH[nom].AGR.valuable

'It's your vote that counts!' (Saipan Tribune, October 1, 1997)

c. Ginin i finu' Juan na ma-tungu' as nana-ña yan from the word Juan COMP AGR.PASS-know OBL mother-AGR and tata-ña father-AGR 'It was from Juan's words that it was known by his mother and father.' (Cooreman 1983, 86)

d. I hälum guma' ha' nai siña man-laoya hit _. the inside house EMP COMP can AGR-walk.around we 'We can wander around only inside the house.' (Ginen i Obispo, March 7, 1999)

As before, the dependency between the focus and the gap meets the familiar criteria for $w h$-movement. The analytic issue is whether the focus has itself undergone $w h$ movement, or is instead the predicate of an HRC.

Exactly this issue is raised and then resolved for English wh-clefts by Hankamer (1974), and for English it-clefts by Pinkham and Hankamer (1975). Hankamer and Pinkham establish that certain instances of clefts must be derived by $w h$-movement of the focus, others must be HRCs, and still others can be analyzed either way. Their demonstration relies on two types of arguments that will prove useful in what follows. First, if the focus could not independently serve as the predicate of a clause, it cannot be the predicate of an HRC, but must instead have reached its surface position via $w h$-movement. Second, if the focus exhibits connectivity effects linking it to the remainder of the sentence (henceforth, the remainder), it must have undergone wh-movement. But if connectivity might have held but does not, the focus must be the predicate of an HRC. I now bring these and other types of arguments to bear on the analysis of the Chamorro constructions in (7) and (11).

\subsection{Evidence}

This section gives six arguments that certain types of constituent questions and focus constructions in Chamorro must involve $w h$-movement of the interrogative phrase or focus. The combined weight of the evidence makes it clear that direct $w h$-movement is a live option in this language. Evidence is presented from an impossible type of predicate in 5.4.1, from two sorts of connectivity in 5.4.2 and 5.4.3, from sluicing in 5.4.4, from negative concord in 5.4.5, and from a specificity effect in 5.4.6. 


\subsubsection{An Impossible Type of Predicate}

Although Chamorro allows predicates of clauses to be of any major category types, it - curiously - does not permit them to be DPs in the locative case. Compare the PP predicate in (12a) with the locative DPs in $(12 b-c) .{ }^{4}$

(12) a. Ginin as Juan i katta.

from oBL Juan the letter

'The letter was from Juan.'

b. ${ }^{*} \mathrm{Gi}$ petta $\mathrm{i}$ ispehus.

LOC door the mirror

'The mirror is on the door.'

c. *Gi hilu' lamäsa magagu-mu.

LOC top table clothes-AGR

'Your clothes are on top of the table.'

The only predicates that the language has for denoting location in space are verbs; for instance, the verb gaigi 'be at (a location)'.

(13) a. Gaigi gi petta i ispehus.

AGR.be.at LOC door the mirror

'The mirror is on the door.'

b. Gaigi magagu-mu gi hilu' lamäsa.

AGR.be.at clothes-AGR LOC top table

'Your clothes are on top of the table.'

Nonetheless, interrogative phrases can occur in the locative case, as the constituent questions in (14) show.

(14) a. Gi manu ni man-ma'a'ñao i famagu'un mañ-aga _ ? LOC where? COMP AGR-afraid the children INFIN.AGR-stay 'Where are the children afraid to stay?'

b. Giya hayi nai ha-dipépendi gui' si Juan _?

LOC who? COMP AGR-depend.PROG himself UNM Juan

'Who does Juan depend on?'

More generally, focused phrases can occur in the locative case (Chung 1998, 272).

(15) a. Gi hilu' lamäsa nai ha-po'lu si Sally i nä’yan siha _. LOC top table COMP AGR-put UNM Sally the dish PL

'Sally put the dishes on top of the table.'

b. Gi tatti-n ädyu na dos amku' na dumimu i dos _. LOC behind-L that $\mathrm{L}$ two old.one COMP AGR.kneel the two 'It was behind those two old people that the two knelt.' (Cooreman 1983, 71) 
Given that DPs in the locative case cannot be predicates of clauses, examples of the type (14-15) cannot be HRCs. Instead, they must be derived directly by whmovement of the interrogative phrase or focus, as shown in (8).

\subsubsection{Connectivity in Selectional Restrictions}

A predicate's selectional restrictions are generally believed not to extend past its own maximal projection. This locality prevents the verb of the relative clause in English examples like (16) from imposing any selectional restrictions on the constituent following the copula.

(16) a. The island where they went for their vacation was Tinian.

b. The island where they stayed during their vacation was Tinian.

c. *The island where they went for their vacation was to Tinian.

In (16), the subject DP contains a relative clause modifier-either where they went for their vacation or where they stayed during their vacation. The point is that the verb inside the relative clause has no impact on the phrase following the copula (Tinian). If the verb of the relative clause could impose selectional restrictions on this phrase, one might expect (16c) to be grammatical, but it is not.

Consider now the fact that in the English $w h$-clefts in (17), the focus conforms to selectional restrictions imposed by the verb in the remainder.

(17) a. Where they went for their vacation was to Tinian.

b. Where they stayed during their vacation was on Tinian.

c. *Where they stayed during their vacation was to Tinian.

This connectivity is evidence that the focus in these examples must have undergone wh-movement (see Pinkham and Hankamer 1975, 430).

Chamorro exhibits the same sort of connectivity. In the constituent questions below, the interrogative phrase clearly conforms to selectional restrictions imposed by the verb in the remainder. The interrogative phrase in (18a) must be a goal, not a location, because konni' 'take' selects a goal; the interrogative phrase in (18b) must be a location, not a goal, because po'lu 'put' selects a location (compare (18c)).

(18) a. Pära manu guätu nai ma-konni' si Miguel_?

to where? over.there COMP AGR-take UNM Miguel

'To where did they take Miguel?'

b. Manu guätu nai ma-po'lu i famagu'on-ta _ ?

where? over.there COMP AGR-put the children-AGR

'Where did they leave our children?'

c. *Pära manu guätu nai ma-po'lu i famagu'on-ta_?

to where? over.there COMP AGR-put the children-AGR

'To where did they leave our children?' 
Similarly, the focused phrase in the constructions in (19) conforms to selectional restrictions imposed by the verb in the remainder. ${ }^{5}$

(19) a. Ginin Guam nai pära u-fattu si Ramon _ agupa'. from Guam COMP FUT AGR-arrive UNM Ramon tomorrow 'It's from Guam that Ramon will arrive tomorrow.'

b. I hilu' lamäsa na u-po'lu i lepblu si Juan _. the top table COMP AGR-put the book UNM Juan 'It's on top of the table that Juan will put the book.'

These patterns argue that the interrogative phrase or focus in these examples must have undergone $w h$-movement.

\subsubsection{Connectivity in Antecedent-Pronoun Relations}

For a different argument from connectivity, I turn next to the architecture of antecedent-pronoun relations.

Antecedent-pronoun relations in Chamorro must conform to both universal and language-particular restrictions. For instance, Principle $\mathrm{C}$ of the Binding Theory must be observed. One consequence of this principle is that a full DP cannot antecede a pronoun that c-commands it. Consider the examples below, in which the relations symbolized by coindexing are excluded by Principle C. ${ }^{6}$

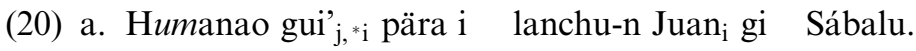
AGR.go he to the farm-L Juan LOC Saturday 'He $\mathrm{j}_{\mathrm{j},{ }^{*} \mathrm{i}}$ went to Juan's $\mathrm{s}_{\mathrm{i}}$ farm on Saturday.'

b. Ha-ipi' pro $_{\mathrm{j},{ }^{*} \mathrm{i}} \mathrm{i}$ niyuk ni machetti-n Pedro ${ }_{\mathrm{i}}$. AGR-split the coconut with machete-L Pedro 'He ${ }_{j,{ }_{j}{ }_{i}}$ split the coconut with Pedro's ${ }_{i}$ machete.'

Over and above this, Chamorro imposes the demand that a full DP either c-command, or else occur to the left of, any pronoun that it antecedes (see Chung 1998, 73-80). This requirement can be seen at work in the following.

(21) a. Ha-lachai i nä'-ña pro $\mathrm{i}_{\mathrm{i}} \operatorname{taotao}_{\mathrm{i}}$ AGR-consume the food-AGR the person

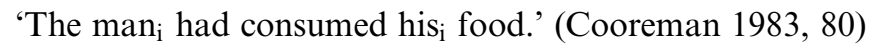

b. In-kenni' i famagu'on-ña pro $_{\mathrm{j},{ }^{*}{ } \mathrm{i}}$ pära $\mathrm{i}$ gima' Mr. Reyes ${ }_{\mathrm{i}}$. AGR-take the children-AGR to the house Mr. Reyes 'We took his ${ }_{\mathrm{j},{ }^{*}{ }_{\mathrm{i}}}$ children back to Mr. Reyes' ${ }_{\mathrm{i}}$ house.'

In each of these examples, a full DP is attempting to antecede a possessor pronoun that occurs to its left. The relation is legal in (21a), because the full DP is the subject, and therefore c-commands the rest of the clause, including the pronoun. ${ }^{7}$ But in (21b), the c-command condition is not met, and so coindexing is ruled out. 
How do antecedent-pronoun relations work in constituent questions and focus constructions? If these constructions were invariably HRCs, we might expect a full DP embedded in the interrogative phrase or focus to be able to antecede a pronoun embedded in the remainder. The coindexing would observe Principle $\mathrm{C}$, since the pronoun - a subconstituent of the HR - would not c-command the name. It would also satisfy the Chamorro-specific requirement, since the name-a subconstituent of the interrogative phrase or focus - would occur to the left of the pronoun. Further, we might expect a full DP embedded in the remainder to be unable to antecede a pronoun embedded in the interrogative phrase or focus. In such a configuration, the Chamorro-specific requirement would be violated, since the name-a subconstituent of the HR - would neither c-command the pronoun nor occur to its left.

Neither of these predictions is correct. There are examples in which a full DP embedded in the interrogative phrase or focus cannot antecede a pronoun embedded in the remainder.

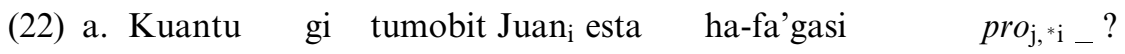
how.many? LOC car Juan already wH[obj].AGR-wash

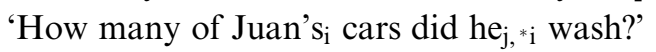

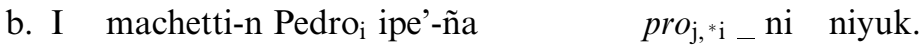
the machete-L Pedro WH[obl].split-AGR OBL coconut 'He $\mathrm{j}_{\mathrm{j},{ }^{*} \mathrm{i}}$ split the coconut with Pedro's ${ }_{i}$ machete.'

There are also examples in which a full DP embedded in the remainder can antecede a pronoun embedded in the interrogative phrase or focus.

(23) a. Kuantu gi tumobet-ña pro $_{\mathrm{i}}$ esta ha-fa'gasi si $\mathrm{Juan}_{\mathrm{i}_{-}}$? how.many? LOC car-AGR already wH[obj].AGR-wash UNM Juan

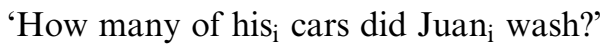

b. Gi gima'-ña proi na in-bisita $\mathrm{i}$ biha $_{\mathrm{i}} \ldots$. LOC house-AGR COMP AGR-visit the old.lady

'It was at her $\mathrm{i}_{\mathrm{i}}$ house that we visited the old lady.

These patterns are connectivity effects-more precisely, reconstruction effects. To see this, suppose that Principle $\mathrm{C}$ must be satisfied under reconstruction, and that the Chamorro-specific requirement can be met under reconstruction as well. Suppose further that the interrogative and focused phrases in (22-23) have undergone wh-movement. Then the coindexing in (22) will be excluded by Principle $\mathrm{C}$ under reconstruction, as in (20). But the coindexing in (23) will be legal, because under reconstruction it respects both Principle $\mathrm{C}$ and the Chamorro-specific requirement; compare (21a).

The view that reconstruction effects arise only through movement is not universally held. Nonetheless, there is evidence from other languages that this view is correct as far as clefts in particular are concerned (see Hankamer 1974 on English 
wh-clefts). I therefore take the patterns just exhibited to argue that (22-23) are not HRCs; rather, the interrogative phrase or focus must have undergone whmovement. ${ }^{8}$

\subsubsection{Sluicing}

Further evidence that Chamorro has some constituent questions that are not HRCs is provided by the ellipsis process known as sluicing.

Merchant (2001) establishes that sluicing in numerous languages conforms to the following generalization: exactly those languages that allow a preposition to be stranded under $w h$-movement also allow a preposition to be stranded in (the elided IP of) sluicing. English, for instance, can strand prepositions under wh-movement and in sluicing, as (24) shows, but French cannot strand prepositions in either construction.

(24) a. Who was she talking to?

b. We know she was talking to someone, but we don't know [who $]_{-}$.

Merchant uses this generalization to argue that sluicing is derived by deletion of a fully articulated IP from which the interrogative phrase has been extracted by whmovement.

Surprisingly, Merchant's generalization appears to make the wrong predictions about sluicing in the Austronesian language Malagasy. Potsdam (2003) observes that Malagasy cannot strand prepositions under wh-movement, but seems to be able to strand prepositions in the material elided by sluicing. Compare the Malagasy examples in (25).

(25) a. *Trano iza no mitoetra amina i Rasoa?

house which? PRT live.ACT in Rasoa

'Which house does Rasoa live in?' (Potsdam 2003, 13)

b. Mitoetra amin' ny trano i Rasoa fa hadinoko hoe trano [iza ${ }_{-}$].

live.ACT in the house Rasoa but forget.1SG COMP house what?

'Rasoa lives in a house but I forget which house.' (Potsdam 2003, 13)

Potsdam's account of this builds on the claim that sluices - and, in fact, all constituent questions - in Malagasy are HRCs (see Paul and Potsdam 2004). This means that the constituent elided by Malagasy sluicing is not an IP, but instead an HR, and the interrogative phrase that survives this ellipsis in (25b) is not the object of a stranded preposition, but the predicate of an HRC. Given that the elided HR in (25b) can be formed from an applicative clause in which no preposition has been stranded, the end result is that sluicing in Malagasy does not constitute a counterexample to Merchant's generalization after all.

Now, Chamorro does not permit overt prepositions to be stranded under whmovement. 
(26) a. Ginin hayi na un-risibi i katta _ ?

from who? COMP AGR-receive the letter

'From whom did you receive the letter?'

b. *Hayi un-risibi i katta ginin_?

who? AGR-receive the letter from

'Who did you receive the letter from?'

The language also has a version of sluicing.

(27) Mam-ómoksai mannuk, lao ti ta-tungu' [hafa na klasi_ ].

AGR.AP-raise.PROG chicken but not AGR-know what? L type

'He's raising chickens, but we don't know what kind.'

This makes it relevant to ask whether Chamorro resembles French in conforming straightforwardly to Merchant's generalization, or whether it resembles Malagasy in appearing, at least initially, to offer a counterexample. If Chamorro, like French, cannot strand a preposition in the elided IP of sluicing, this would be consistent with the claim that some constituent questions in the language - those in sluicingare derived by $w h$-movement of the interrogative phrase. On the other hand, if Chamorro were to pattern like Malagasy in permitting sluicing constructions of the type (25b), we would have a reason to follow Potsdam and Paul in proposing that all constituent questions in the language, including sluices, were HRCs.

In fact, Chamorro cannot strand a preposition in the elided IP of sluicing (Chung 2006). Compare (28a), in which the preposition ginin 'from' has been pied-piped, with the ungrammatical (28b), in which the preposition has been stranded inside the ellipsis.

(28) a. Si Joe ha-hunguk i istoria ginin guahu, lao ti hu-tungu' [ginin UNM Joe AGR-hear the story from me but not AGR-know from kuantu más na taotao _ ].

how.many? more LNK person

'Joe heard the story from me, but I don't know from how many others.'

b. * $\mathrm{Si}$ Joe ha-hunguk i istoria ginin guahu, lao ti hu-tungu'

UNM Joe AGR-hear the story from me but not AGR-know

[kuantu más na taotao _ ].

how.many? more LNK person

'Joe heard the story from me, but I don't know how many others.'

The contrast between this and the Malagasy pattern in (25) is striking. It is reinforced by the observation that Chamorro, like Malagasy, does have a potential source for (28b) that could in principle be analyzed as an HRC, and in which no overt preposition has been stranded. Consider (29), in which one could treat the interrogative phrase as a predicate and the remainder, as an HR with a locative DP gap. 
(29) $\mathrm{Si}$ Joe ha-hunguk i istoria ginin guahu, lao ti hu-tungu' kuantu UNM Joe AGR-hear the story from me but not AGR-know how.many? más na taotao [ $O$ nai ha-hunguk _ ]. more LNK person COMP AGR-hear 'Joe heard the story from me, but I don't know how many others he heard it (at).'

Why is it impossible to derive (28b) from (29) by eliding the apparent HR? The most straightforward answer is that Chamorro sluicing - like sluicing in many other languages, but unlike Malagasy sluicing - is unable to elide HRs. The important point is that, for whatever reason, sluicing cannot derive (28b) from (29). This strongly suggests that a Malagasy-style analysis that would treat all constituent questions as HRCs is inappropriate for Chamorro. Instead, at least some constituent questions in the language - namely, those truncated by sluicing — are derived by whmovement of the interrogative phrase.

\subsubsection{Negative Concord}

Further evidence that not all focus constructions are HRCs comes from the workings of negative concord.

Sentential negation in Chamorro is expressed by means of elements that occur in the vicinity of the clause's left edge: the negative $t i$ 'not' (see (30a)), various negative verbs (30b), and - in the focus construction - a negative focus (30c).

(30) a. Ti siña hao um-iskuela gi más tákkilu' na iskuela. not can you AGR-go.to.school LOC more high L school 'You couldn't go to school in a higher school.' (Cooreman 1983, 152)

b. Taya' néngkanu' guihi na tiempu. AGR.not.exist food LOC.that $\mathrm{L}$ time 'There wasn't any food at that time.' (Cooreman 1983, 50)

c. Ni unu siña ta-sokni nu esti na chinätsaga. not one can AGR-blame OBL this L hardship 'We can blame no one for this hardship.' (Saipan Tribune, December 15, 1998)

Importantly, elements that express sentential negation can license the appearance of other morphologically negative forms that do not contribute any (separate) negation to the semantics. This phenomenon, known as negative concord, is illustrated below.

(31) a. Ti hu-bisita ni háyiyi ha'. not AGR-visit not anyone EMP 'I didn't visit anyone.' 
b. Ti in-li'i' si Dolores ni mánunu ha'. not AGR-see UNM Dolores not anywhere EMP 'We didn't see Dolores anywhere.'

c. Esti na tronku-n nunu ti pinätcha ni háfafa ha' na distrosu. this $\mathrm{L}$ tree-L banyan not AGR.PASs.touch not any EMP L disaster 'This banyan tree was not touched by any destruction.' (Cooreman 1983, 176)

d. Taya' ni unu tumaitai ni háfafa ha'. AGR.not.exist no one WH[nom].read not anything EMP 'There wasn't anyone who read anything.'

I will refer to the left-edge elements that express sentential negation in Chamorro as expressors of negation, and to the morphologically negative forms they license as negative concord phrases.

As in other languages (see Ladusaw 1992), c-command plays a crucial role in the licensing of negative concord: negative concord phrases in Chamorro must fall within the c-command domain of an expressor of negation. This can be seen from the contrast between (31) and (32). The negative concord phrases in (31a-c) are c-commanded and licensed by the negative $t i$ 'not', a functional head whose c-command domain includes the verb phrase. The negative concord phrases in (31d) - both subconstituents of the DP complement of taya' 'not exist' - are ccommanded and licensed by this negative verb. But the negative concord subject in (32a) is not licensed, evidently because it falls outside the c-command domain of $t i$. And in (32b), one negative concord phrase c-commands the other, but neither is licensed, because there is no expressor of negation to serve as the licenser. ${ }^{9}$

(32) a. *Ti mattu nigap ni háfafa ha'. not AGR.arrive yesterday not anything EMP 'Nothing arrived yesterday.'

b. *Hagu, pära un-sangan ni háfafa ha' ni pära hayi put esti. you FUT AGR-say not anything EMP not to anyone about this 'As for you, you're to say nothing to anyone about this.'

Observe now that in the focus construction, a negative focus can license negative concord in the remainder (see Chung 1998, 273).

(33) a. Ni unu lumi'i’_ si Dolores ni mánunu ha'. not one WH[nom].see UNM Dolores not anywhere EMP 'No one saw Dolores anywhere.'

b. Ni háfafa ha' ma-tätaitai_ _ni unu giya hämi. not anything EMP WH[nom].AGR.PASS-read.PROG not one LOC us 'Nothing had been read by any one of us.' 
In order for the negative concord phrases in (33) to be licensed, they must fall within the c-command domain of the negative focus. But that could not happen if the focus were the nonverbal predicate of an HRC and the remainder were its subject, an HR, because the predicate phrase does not c-command the subject in Chamorro (see Chung 2005). One indication that this is so can be recovered from the preceding discussion. Recall from (31-32) that the negative $t i$ c-commands the verb phrase but not the subject. If we assume (as seems reasonable) that predicate phrases occupy a uniform structural position in Chamorro whatever their category type, then it follows that predicate phrases more generally do not c-command the subject. The HRC analysis, then, arrives at an impasse.

The alternative is that the negative focus in these examples has undergone $w h$ movement, and therefore occupies the specifier of $\mathrm{C}-\mathrm{a}$ position from which it c-commands the remainder. Under this analysis, the negative concord phrases in (33) will be c-commanded and licensed in a completely unexceptional way. The success of this account argues that in constructions of the type (33), the focus must have undergone wh-movement.

\subsubsection{A Specificity Effect}

My last argument for $w h$-movement in constituent questions and focus constructions is supplied by a Chamorro specificity effect.

In Chamorro, subjects that are external arguments and that surface within the clause must be specific, in the following sense (see Chung 1998, 102-106). They can be realized as pronouns, proper names, definite DPs, or DPs headed by the indefinite article un 'a, one', a numeral, or pälu '(contrastive) some'.

(34) a. Mang-onni' yu' lahyan na taotao pära taotao-hu. AGR.AP-take I plenty L person for person-AGR 'I took many people as my subordinates.' (Cooreman 1983, 34)

b. Sigi di um-äñangun i dos umäsagua. keep.on AGR-whisper.to.ea.other the two married.ones 'The two married people kept on whispering.' (Cooreman 1982, 77)

But they cannot be realized as DPs headed by the null nonspecific article or by a (weak or strong) quantifier.

(35) a. *Mañ-áchalik lalahi. AGR-laugh.PROG men

'Men laughed.'

b. *Ha-tungu' meggai na taotao si tata-hu. AGR-know many L person UNM father-AGR 'Many people know my father.' 
Subjects that are internal arguments are not similarly restricted, as (36) is intended to suggest.

(36) a. Änai ma-bäba, humuyung patgun. when AGR-open AGR.come.out child

'When they opened it, a child emerged.' (Cooreman 1983, 107)

b. Pära u-ma-na'i todu i mätai ni iyo-nña.

FUT AGR-PASS-give all the dead OBL possession-AGR

'Every dead person should be given his belongings.' (Cooreman 1983, 9)

Unsurprisingly, subjects that are external arguments exhibit the specificity effect even when they are realized as HRs. ${ }^{10}$

(37) a. Áttilung i $O$ gaigi _ gi halum kahita.

AGR.black the WH[nom].AGR.be.at LOC inside box

'The thing that was in the box was black.'

b. *Áttilung $O$ gaigi_ gi halum kahita.

AGR.black WH[nom].AGR.be.at LOC inside box

'A thing that was in the box was black.'

Subjects of DP predicates exhibit the specificity effect as well. This is expected, given that DP predicates are individual-level, and so their subjects are external arguments (see, e.g., Diesing 1992; Chierchia 1995).

(38) a. Lao ti mansiudadanu-n America lokkui' i natibu guini? but not citizens-L America also the indigenous here

'But aren't the local people here also American citizens?' (Saipan Tribune, February 8, 2000)

b. I'isao esti i $O$ ginin batchit sinner this the IMPERF WH[nom].AGr.blind

'This one who had been blind was a sinner.' (Ginen i Obispo, March 14, 1999)

c. *Impleáo i gubietnu meggai na taotao Sa’ipan. employee the government many L person Saipan

'Many Saipanese people are government employees.'

With this information in hand, let us now turn to constituent questions and focus constructions in which the interrogative phrase or focus happens to be a DP. If these constructions are HRCs, their DP predicate ought to be individual-level, and so their subject, the HR, ought to be an external argument. The HR should therefore exhibit the specificity effect.

Chamorro does have examples that are consistent with this prediction. The HR in the constituent question in (39a) is headed by a demonstrative; the HR in the (apparent) focus construction in (39b) is headed by the definite article. ${ }^{11}$ 
(39) a. Hayi ädyu i $O$ pära u-fahani-n maisa gui _ present?

who? that the FUT WH[nom].AGR-buy.for-L self him present

'Who is that one who's going to buy a present for himself?'

b. Bos palao'an i $O$ um-agang huyung _.

voice woman the $\mathrm{WH}[\mathrm{nom}]-$ call out

'What called out was a woman's voice.'

Examples of this sort, however, are clearly in the minority. In most types of constituent questions and focus constructions, the remainder is not headed by any overt determiner. This means that (in an HRC analysis) the remainder is an HR headed by the null nonspecific article, or else (in the $w h$-movement analysis) the remainder is a constituent not headed by D at all-in other words, IP. See the examples cited earlier, as well as

(40) a. Hafa gaigi__ gi tatti-n petta-n gima'-ñiha. what? WH[nom].AGR.be.at LOC behind-L door-L house-AGR

'[Not even I know] what is behind the door of their house.' (Saipan Tribune, December 10, 1998)

b. Más ki 1,100 na bisnis ma-huchum petta-nñiha _. more than $1,100 \mathrm{~L}$ business AGR.PASS-close door-AGR 'More than 1,100 businesses have closed their doors.' (Saipan Tribune, December 19, 1998)

Either way, the putative HR is not formally marked as specific - a pattern difficult to square with the predictions of the HRC analysis. In this sense, the specificity effect argues that the constructions in (40) are not HRCs; rather, they are derived by whmovement of the interrogative phrase or focus.

One might wonder whether this line of reasoning could be defused. For instance, it might be suggested that because the remainder contributes to the common-ground presupposition of the question or focus construction, it is, in effect, understood as specific. While such a suggestion might seem reasonable, it would leave unexplained why simple DPs lacking an overt determiner cannot be understood as specific in examples like

(41) *Ha-na'ma'a'ñao yu' taklalo'-mu. AGR-make.afraid me anger-AGR

'[What's wrong with anger of mine?] — Anger of yours frightens me.'

In other words, it would remain mysterious why a purely pragmatic approach to the specificity effect seems not to generalize beyond constructions of the type (40).

In short, the specificity effect offers evidence against an HRC analysis of the constructions in (40), and in favor of a wh-movement analysis. 


\subsection{Conclusion}

I hope to have shown that overall, the most direct approach to constituent questions and focus constructions in Chamorro is also the right approach: these constructions can, and in many instances must, be derived by wh-movement of the interrogative phrase or focus. Among the constructions that must be derived by wh-movement are those in which the interrogative or focused phrase surfaces in the locative case (as in (14-15)), shows connectivity with the remainder ((18-19) and (22-23)), licenses negative concord (33), or is a DP (if the remainder is not introduced by any determiner; see (40)). Constructions that must be analyzed as HRCs do occur, but are not nearly as common; see (39). Finally, if the specificity evidence of 5.4.6 is taken seriously, the types of constructions that are structurally ambiguous, in that they are amenable to both analyses, are rather circumscribed: they involve interrogative or focused phrases that are (stage-level) PPs and do not fall into any of the other subclasses just mentioned.

From this (perhaps unremarkable) conclusion, two larger points emerge. First, there are verb-initial Austronesian languages - notably, Chamorro-whose constituent questions and focus constructions are not exclusively HRCs. Second, the existence of languages like Chamorro significantly increases the challenge of attempting to correlate verb-first order with the absence of $w h$-movement.

\section{Notes}

Many thanks to the Chamorro speakers who contributed to this work, especially Priscilla Anderson, Manuel F. Borja, Teresina Garrido, Ray P. Lujan, William I. Macaranas, Maria P. Mafnas, Maria T. Quinata, Anicia Tomokane, and the late Agnes C. Tabor. Thanks also to Judith Aissen and James McCloskey for comments. This chapter is dedicated to David Perlmutter, who taught me syntactic argumentation.

1. For instance, what property of verb-peripheral languages might cause wh-movement of interrogative phrases to be prohibited or dispreferred? What property of headless-relative clefts might make them appropriate for realizing constituent questions?

The following abbreviations are used in the morpheme-by-morpheme glosses: $\mathrm{ACT}=$ active, $\mathrm{AGR}=$ agreement, $\mathrm{AP}=$ antipassive, $\mathrm{COMP}=$ complementizer, $\mathrm{EMP}=$ emphatic, $\mathrm{FUT}=$ future, IMPERF $=$ imperfect, INFIN $=$ infinitive, $\mathrm{L}=$ linker, $\mathrm{LOC}=$ local morphological case, $\mathrm{OBL}=$ oblique morphological case, PASS $=$ passive, $\mathrm{PL}=$ plural, $\mathrm{PROG}=$ progressive, $\mathrm{PRT}=$ focus particle, $\mathrm{SG}=$ singular, $\mathrm{UNM}=$ unmarked morphological case, $\mathrm{WH}=\mathrm{Wh}$-Agreement, nom $=$ nominative, $\mathrm{obj}=$ objective, obl $=$ oblique. Note that infixes in the Chamorro examples are italicized.

2. The null operator $O$ cannot be the object of an overt preposition, because $O$ cannot piedpipe a preposition, and overt prepositions cannot be stranded (see section 5.4.4).

3. Interrogative phrases that are (nonverbal) predicates of clauses always occur in situ. Note that for most speakers, multiple wh-questions are severely degraded. 
4. Readers might wonder why $(12 b-c)$ could not be focus constructions in which the locative DP has been focused. There are (at least) two reasons. First, focused locative DPs are typically separated from the remainder of the sentence by an overt complementizer (compare (15)). Second, the DP in the remainder would have to be interpreted as a DP predicate, but DP predicates are individual-level, and therefore incompatible with locative phrases (see section 5.4.6).

5. The focused location in (19b) occurs in the unmarked morphological case because this is the default case for DPs that occur at the left edge of the clause. Consistent with this, the interrogative and focused phrases in (14-15) could also occur in the unmarked morphological case.

6. In this section (but not in other sections), null pronouns of relevance to the discussion are represented as pro in the Chamorro examples. For discussion of the distribution of null pronouns, see Chung 1998, 29-32.

7. Even if Chamorro's verb-initial order were assumed to be derived via VP raising, there would be a stage of derivation at which the subject - more precisely, the external argumentc-commanded the rest of the clause. For arguments against a VP-raising analysis of Chamorro clause structure, see Chung 2005.

8. Antecedent-pronoun relations can satisfy the c-command condition of the Chamorrospecific requirement under reconstruction. But, as might be expected, they cannot satisfy the precedence condition under reconstruction. See Chung 1998, 148-149.

9. Notice that none of the negative concord phrases in (32) are external arguments. Therefore, none of them would be independently excluded by the specificity effect to be discussed in section 5.4.6.

10. Irrelevantly, some speakers find (37b) grammatical if it is interpreted as 'A black thing was in the box'.

11. I say "(apparent) focus construction" because it is not obvious that any Chamorro constituent is being focused in (39b).

\section{References}

Adger, David, and Gillian Ramchand. 2005. Merge and move: Wh-dependencies revisited. Linguistic Inquiry 36:161-193.

Aldridge, Edith. 2004. Ergativity and word order in Austronesian languages. Doctoral dissertation, Cornell University.

Bauer, Winifred. 1991. Maori ko again. Te Reo 24:31-36.

Carnie, Andrew, Heidi Harley, and Sheila Ann Dooley, eds. 2005. Verb first. Amsterdam: John Benjamins.

Chierchia, Gennaro. 1995. Individual-level predicates as inherent generics. In G. N. Carlson and F. J. Pelletier, eds., The generic book, 176-223. Chicago: University of Chicago Press.

Chung, Sandra. 1998. The design of agreement: Evidence from Chamorro. Chicago: University of Chicago Press.

Chung, Sandra. 2005. What fronts? On the VP-raising account of verb-initial order. In Andrew Carnie, Heidi Harley, and Sheila Ann Dooley, eds., Verb first, 9-29. Amsterdam: John Benjamins. 
Chung, Sandra. 2006. Sluicing and the lexicon: The point of no return. In Rebecca T. Cover and Yuni Kim, eds., Proceedings of the Thirty-First Annual Meeting of the Berkeley Linguistics Society, 73-91. Berkeley: Berkeley Linguistics Society, University of California.

Cooreman, Ann. 1982. Chamorro texts. Ms., University of Oregon, Eugene.

Cooreman, Ann. 1983. Chamorro texts. Ms., Saipan, U.S. Commonwealth of the Northern Mariana Islands.

Diesing, Molly. 1992. Indefinites. Cambridge, MA: MIT Press.

Georgopoulos, Carol. 1991. Syntactic variables: Resumptive pronouns and A'-binding in Palauan. Dordrecht: Kluwer.

Greenberg, Joseph H. 1963. Some universals of grammar with particular reference to the order of meaningful elements. In J. Greenberg, ed., Universals of language, 73-133. Cambridge, MA: MIT Press.

Hankamer, Jorge. 1974. On the non-cyclic nature of Wh-clefting. In M. W. Lagaly, R. A. Fox, and A. Bruck, eds., Papers from the Tenth Regional Meeting of the Chicago Linguistic Society, 221-233. Chicago: Chicago Linguistic Society.

Ladusaw, William. 1992. Expressing negation. In C. Barker and D. Dowty, eds., Proceedings of the Second Conference on Semantics and Linguistic Theory, 237-259. Columbus: Department of Linguistics, Ohio State University.

Merchant, Jason. 2001. The syntax of silence: Sluicing, islands, and the theory of ellipsis. Oxford: Oxford University Press.

Oda, Kenji. 2005. V1 and wh-questions: A typology. In Andrew Carnie, Heidi Harley, and Sheila Ann Dooley, eds., Verb first, 107-133. Amsterdam: John Benjamins.

Paul, Ileana, and Eric Potsdam. 2004. Sluicing without wh-movement in Malagasy. Delivered at CLS 40.

Pinkham, Jessie, and Jorge Hankamer. 1975. Deep and shallow clefts. In R. E. Grossman, L. J. San, and T. J. Vance, eds., Papers from the Eleventh Regional Meeting of the Chicago Linguistic Society, 429-450. Chicago: Chicago Linguistic Society.

Potsdam, Eric. 2003. Ellipsis identity and Malagasy sluicing. Delivered at NELS 33.

Potsdam, Eric. 2004. Wh-questions in Malagasy. Delivered at AFLA 11.

Seiter, William. 1975. Information questions in Philippine languages. Ms., University of California, San Diego. 